\title{
A Preliminary Investigation of the Effect of Ethical Labeling and Moral Self-Image on the Expected and Perceived Flavor and Aroma of Beer
}

\author{
George Van Doorn $^{1,2, *(\mathbb{D})}$, Rose Ferguson ${ }^{3}(\mathbb{D})$, Shaun Watson ${ }^{2,4} \mathbb{( D}^{\text {, Justin Timora }}{ }^{3} \mathbb{( D}$, Dylan Berends ${ }^{5}$ \\ and Chris Moore ${ }^{6}$ \\ 1 School of Science, Psychology, and Sport, Churchill Campus, Federation University Australia, \\ Churchill, VIC 3842, Australia \\ 2 Health Innovation \& Transformation Centre, Mt Helen Campus, Federation University Australia, \\ Ballarat, VIC 3350, Australia; shaun.watson@federation.edu.au \\ 3 School of Science, Psychology, and Sport, Berwick Campus, Federation University Australia, \\ Berwick, VIC 3806, Australia; r.ferguson@federation.edu.au (R.F.); j.timora@federation.edu.au (J.T.) \\ 4 School of Science, Psychology, and Sport, Mt Helen Campus, Federation University Australia, \\ Ballarat, VIC 3350, Australia \\ 5 Little Gippsland Brewing Company, 55 Grey Street, Traralgon, VIC 3844, Australia; enquiry.lgbc@gmail.com \\ 6 Sailors Grave Brewing Company, 7 Forest Road, Orbost, VIC 3888, Australia; chris@sailorsgrave.net \\ * Correspondence: george.vandoorn@federation.edu.au; Tel.: +61-3-5122-6746
}

check for updates

Citation: Van Doorn, G.; Ferguson, R.; Watson, S.; Timora, J.; Berends, D.;

Moore, C. A Preliminary Investigation of the Effect of Ethical Labeling and Moral Self-Image on the Expected and Perceived Flavor and Aroma of Beer. Beverages 2021, 7, 42. https://doi.org/ 10.3390/beverages7020042

Academic Editors: Pavel Dostálek, Luis F. Guido and Koushik Adhikari

Received: 3 May 2021

Accepted: 16 June 2021

Published: 18 June 2021

Publisher's Note: MDPI stays neutral with regard to jurisdictional claims in published maps and institutional affiliations.

Copyright: (c) 2021 by the authors. Licensee MDPI, Basel, Switzerland. This article is an open access article distributed under the terms and conditions of the Creative Commons Attribution (CC BY) license (https:/ / creativecommons.org/licenses/by/ $4.0 /)$.

\begin{abstract}
Ethical labelling has been shown to influence taste/flavour perception. Across two experiments, the present study examined how ethical labelling and moral self-image influenced both the expected (Experiment One) and perceived (Experiment Two) taste/flavour characteristics of beer. In Experiment One, 170 participants read either a 'moral' or 'control' label describing a brewery, after which they were presented with an image of a beer. Participants then completed a Beer Taste Perception Questionnaire and the Moral Self-Image Scale. In Experiment Two, 59 participants were exposed to either the moral or control label before tasting a beer and completing the same questionnaires from Experiment One. The results of Experiment One indicated that label type moderated the relationship between moral self-image and the intensity ratings of the beer. Specifically, in the presence of a control label, the expected intensity of the beer's flavour increased as moral self-image increased. Experiment Two found no evidence that the moral label influenced the perceived taste of the beer. However, the results showed that as moral self-image became more positive the perceived refreshingness of the beer increased. This study provides novel evidence of the potential relationship between an individual's moral self-image and the expected and perceived taste/flavour characteristics of beer.
\end{abstract}

Keywords: beer; taste; flavour; expectations; perception; morality

\section{Introduction}

In Australia, craft beer production has grown from a small industry comprised predominantly of home-brew enthusiasts to a large industry worth approximately AUD 370 million (approximately 5\% of the AUD 6.5 billion total annual beer sales in Australia [1]). This growth is not isolated to Australia, and is consistent with the burgeoning craft beer market in other countries [2]. Craft brewers, who spend considerable time in product development and have limited capital to buffer against product failure, are concerned with productintrinsic and product-extrinsic features that influence people's expectations and perception of their products. It is worth keeping in mind here that although price (e.g., value for money) is an important factor in determining consumer behaviour [3], it is not the only factor influencing purchasing decisions. Previous research has shown that beer taste is influenced by factors such as packaging [4], music [5], and glass shape [6]. Little is known, however, about the effect of ethical information and individual difference factors on consumers' perceptions of beer. This preliminary study is the product of a discussion between 
the authors and the Little Gippsland Brewing Company, who donate $100 \%$ of their profits to the local community.

\section{The Influence of Ethical Labelling}

In competitive markets like the food and beverage industries, companies need to use innovative marketing strategies to sway consumer preferences in favor of their brands and products. One increasingly common strategy to achieve this is the use of ethical labelling. Ethical labelling is a marketing strategy in which products are promoted alongside information about ethical practices used in their production [7]. These labels typically refer to the environmental impact of production (e.g., sustainable, eco-friendly, anti-waste, carbon neutral), the treatment of workers (e.g., fair pay), trading practices (e.g., fair trade), or animal welfare (e.g., free range, humane).

The inclusion of ethical labels represents an attempt to moralise products; that is, to imbue them with moral characteristics via a process of association [8,9]. Food and beverage products are, in and of themselves, morally neutral. There is nothing inherently moral or immoral about an apple, a chocolate bar, or a bottle of wine. However, pairing these products with information about ethical practices associates them with ethical values, such that they may then be perceived as possessing moral characteristics. This, in turn, increases their subjective value $[10,11]$ and the consumers' willingness to purchase them [12]. Indeed, research has found that a majority of participants are willing to pay more for ethicallylabelled products than for equivalent non-ethical alternatives [12-17].

Preference for ethically labelled products is not necessarily driven by the consumers' desire to support ethical practice. Rather, research suggests that ethical labels may influence consumer preferences because they impact beliefs about the quality of the products (i.e., a halo effect). The 'halo effect' is a perceptual bias whereby a salient characteristic of a product distorts the overall impression of that product [18]. This effect is curious, given that the practices signified by the ethical labels typically have no impact on the physical properties of the product, and thus have no objective impact on quality, healthiness, or taste. For example, Bratanova et al. [19] found that participants rated the expected quality of tomato sauce, biscuits, chocolate, and apple juice as higher if these products were presented with ethical labels (e.g., fair-trade), relative to the same products presented with no label or with a negative label (e.g., associated with harmful production practices). Participants also reported that they expected ethically labelled products to taste better than non-ethical alternatives. Similarly, Samant and Seo [20] found that participants who demonstrated a high level of understanding regarding label claims rated chicken breasts labelled as 'organic' as being of higher quality than unlabelled chicken.

Research also suggests that ethical labelling can impact expectations of taste. Napolitano et al. [21] found that beef accompanied by information about animal welfare was expected to taste better than beef that did not include this information. Other research investigating perception, rather than expectations, has found that products with ethical labels are rated as tasting significantly better than those that are unlabelled, and this finding holds across a range of food and beverage products, such as coffee [7], green tea [22], grapes [23,24], chocolate [25], and meat [26]. Related research has also found that ethicallylabelled products are perceived by participants as healthier than identical, non-labelled products $[7,23,24,27,28]$. These findings suggest that product-extrinsic 'ethical' information can influence people's perception of, and expectations relating to, the product itself.

\section{Ethical Labelling and Moral Self-Image}

Research suggests that only $5 \%$ of consumers can be classified as ethical consumers (i.e., driven by their motivation to uphold ethical values and make purchasing decisions based on their moral beliefs; [29]). To most consumers, ethical benefits are either an after-thought (e.g., brand status and perceived quality are more pressing concerns) or are not considered at all. Further research suggests that only about $55 \%$ of consumers are attentive to ethical information on product packaging and consider this in their decision-making [13]. This 
figure suggests that many consumers place little-to-no importance on ethical information. However, this seems inconsistent with the aforementioned research that suggests positive effects of ethical labelling.

Despite the limited number of consumers prioritizing ethical information when purchasing products, the literature on ethical labelling suggests that the effect of ethical labels on beliefs about, and the perceived taste of, food and beverage products is not limited to consumers who feel strongly about ethical practices [30]. Researchers have found significant effects of ethical labels across samples which are presumably a blend of people varying in terms of how ethically motivated they are. This suggests that it is not necessary for participants to already hold ethical-consumer motives to be influenced by ethical labels.

There is reason to assume that individual differences in morality other than consumer motives may influence the way consumers respond to ethical labels. Moral self-image may moderate the effect of ethical labels on consumer preferences. Moral self-image refers to the moral component of a person's self-concept and reflects their evaluations of how virtuous they perceive themselves to be [31]. A person with a positive moral self-image is one who views themselves as morally good and virtuous relative to other people, whereas a person with a negative moral self-image is one who views themselves as less moral or virtuous than other people. Research in moral psychology suggests that people are motivated to maintain a positive moral self-image to protect their global selfevaluations [32]. Engaging in behaviour that is consistent with your moral values and moral self-image is one strategy to achieve this. Consistent with this idea, research in the domain of ethical labelling has found that moral self-perceptions independently predict preferences for ethical products above and beyond other factors such as knowledge of, and attitudes towards, the product [33]. This occurs specifically because purchasing ethical products affirms participants' identities and values, and leads to positive affect. Thus, participants with a positive moral self-image may respond more strongly to ethical labels than people who have a less positive moral self-image, because preferencing these products affirms their existing self-perceptions.

There is also reason to expect that moral self-perceptions influence the expected and perceived taste of ethical products. This may occur because people with a more positive moral self-image are especially likely to experience an increase in positive affect $[22,25]$ or moral satisfaction [19] when they purchase ethical products due to the aforementioned affirmation of self-perceptions represented by purchasing these products. Moral satisfaction has been shown to mediate the effect of ethical labels on the expected taste of foods such as tomato sauce [19]. Similarly, positive affect has been shown to mediate the effect of ethical labels on the perceived taste of chocolate [25] and green tea [22]. That is, participants in these studies rated the expected and perceived taste of the ethically labelled products as better than identical, non-labelled alternatives because they felt either greater moral satisfaction or positive affect when presented with them.

\section{The Present Study}

Although studies have explored the effect of ethical labelling on taste/flavour perception in beverage products such as coffee and tea, to the best of our knowledge no research has investigated beer; specifically, how ethical labelling influences the expectations and perceptions associated with flavour and aroma. Beer has a complex flavour profile $[34,35]$, which makes it a good candidate for research because its attributes are difficult to describe. Beer is also important from a social perspective. Beer is one of the world's oldest manufactured drinks [36] and one of the world's most consumed beverages [37]. Given this information, it is surprising that research has not assessed the role that ethical labelling plays in the perceived taste of beer.

It was predicted that, given previous work, ethical labelling would influence the expected (Experiment One) and perceived (Experiment Two) taste/flavour of beer. Based on previous research, it was hypothesised that those people provided with the ethical beer label would like (and be willing to pay more for) the beer, compared to those provided 
with a control label. Considering the work of O'Connor et al. [33], it was hypothesised that people scoring high on the moral self-image scale would be willing to pay more for a beer than those people scoring lower. Lastly, it was hypothesised that people scoring high on the moral self-image scale would rate the beer with ethical labelling as being of better quality, and like it more.

\section{Experiment One: Expectations}

\subsection{Method}

Participants

The participants were 170 individuals ( 86 men, 84 women) from the general Australian population, with a mean age of 32.50 years $(S D=10.66$; range $=18$ to 69 years). Although a total of 232 people logged in and agreed to take part in the survey, 61 respondents were excluded prior to data analysis because they (a) did not answer any questions on the survey $(n=14)$, (b) answered fewer than half of the items in the survey $(n=45)$, (c) provided the same response to all questions (e.g., a one (1) for all items; $n=2$ ), or (d) were deemed to be an outlier ( $n=1$; see Section 5.5.1 below). Participants had to be over 18 years of age to participate, as this is the minimum age for the legal consumption of alcohol in Australia. The majority of the participants self-reported that they consumed beer more than once a week $(27.6 \%)$, with the remainder consuming beer either (a) less than once a month $(24.7 \%)$, (b) once a week $(24.7 \%)$, or (c) more than once a month but less than once a week $(22.9 \%)$. An a priori power analysis indicated that a sample size of 128 would yield power of $80 \%$ to detect medium-sized effects of at least $0.25(\alpha=0.05)$.

\subsection{Materials}

Participants completed a web-based survey through SurveyMonkey ${ }^{\mathrm{TM}}$. The survey consisted of one of two labels (i.e., moral or control) and three questionnaires: (a) a demographics questionnaire, (b) the Beer Taste Perception Questionnaire (see Appendix A), and (c) the Moral Self-Image Scale (MSIS).

\subsubsection{Demographics Questionnaire}

To gather demographic and other information, a questionnaire was used that asked participants to provide their age, gender, and drinking habits (e.g., how often they consume beer). The questions relating to drinking habits were answered on four-point response scales ranging from less than once a month to more than once a week.

\subsubsection{Beer Taste Perception Questionnaire}

A questionnaire was developed to measure beer flavour and aroma expectations (Experiment 1) and perceptions (Experiment 2). This questionnaire consisted of nine items that measured different taste and smell characteristics of beer: pleasantness of taste, pleasantness of aftertaste, pleasantness of aroma, intensity of taste, sweetness, fruitiness, bitterness, quality, and willingness to pay. These items were selected for a variety of reasons. First and foremost, each item was chosen for its comparability with past studies. Sweetness, bitterness, fruitiness, and intensity of taste have all been established as key sensory attributes of beer [38]. Second, pleasantness of taste and aftertaste, quality, and willingness-to-pay are all global valence judgements which have been used in previous research [6]. Past research [39] has established that participants are able to evaluate the global (e.g., pleasantness) and specific (e.g., sweetness) characteristics of beer uniquely.

Participants responded to eight items on an eleven-point Likert-type scale, which ranged from 0 (Not___ at all) to 10 (Extremely___ . For example, the question "how pleasant would you rate the taste of the beer?" had response options ranging from Not pleasant at all to Extremely pleasant. The item relating to willingness-to-pay was answered by providing a monetary amount (in Australian dollars) of how much each person would pay for a full glass of the beer which they were shown in the experiment. Items in this questionnaire were randomised to control for order effects. 


\subsubsection{Moral Self-Image Scale (MSIS)}

The MSIS measured participants' evaluations of how moral they believe they are. Participants reported their evaluations of how caring, compassionate, fair, friendly, generous, hard-working, helpful, honest, and kind they are on a 7-point Likert-type scale, ranging from one (Much less than the person I want to be) to seven (Much more than the person I want to be). An example of an MSIS item is "Compared to the honest person I want to be, I am ... ". Moral self-image scores were calculated by summing all items to generate a total score, and then dividing the total score by the number of items on the MSIS. High scores indicate a greater tendency to believe that the person is virtuous. Jordan et al. [31] reported that the MSIS has good reliability $(\alpha=0.88)$. In this study, the internal consistency of the MSIS was found to be acceptable $(\alpha=0.75)$.

\subsubsection{Ethical Labels}

Participants were presented with one of two vignettes (see below) presented as a block of text on a separate page of the online survey. The first was designated the 'ethical' label, whereas the second was the 'control' label. The labels differed only with regard to the additional 'ethical' information on the 'ethical' label (italics are added to the ethical vignette below to highlight the differences, but did not appear in experimental stimuli). Both labels are based on existing, real-world information from the Little Gippsland Brewing Company's [40] website: https:/ /www.littlegippslandbrewing.com.au/.

\subsection{5. 'Ethical' Label Text}

Who Is the Little Mountain Brewing Company?

We are a small collective of like-minded people who wanted to make a great beer, and help the community. Located in eastern Victoria where the water is clear and the air is fresh, we decided to set up our brewery to make beer using only the finest ingredients, and donate all the profits from the beer we sell to community projects. When you drink one of our beers, enjoy it knowing that you are drinking a beer made to the highest standards, and raising money for the local community at the same time. Here's to great beer. Cheers!

\subsection{6. 'Control' Label Text}

Who Is the Little Mountain Brewing Company?

We are a small collective of like-minded people who wanted to make a great beer. Located in eastern Victoria where the water is clear and the air is fresh, we decided to set up our brewery to make beer using only the finest ingredients. When you drink one of our beers, enjoy it knowing that you are drinking a beer made to the highest standards. Here's to great beer. Cheers!

\subsection{Procedure}

After reading an explanatory statement that outlined that the responses would be anonymous, participants provided informed consent by selecting an "I agree to participate" button. The study was conducted in accordance with the (Australian) National Health and Medical Research Council (NHMRC) National Statement on Ethical Conduct in Human Research, and the protocol was approved by Federation University Australia's Human Research Ethics Committee (Project number: A18-021). Participants were made aware of, and recruited to participate in, the online survey via social media (e.g., advertisements posted to Facebook). The survey was hosted on SurveyMonkey. After reading an explanatory statement, participants completed the demographics questionnaire. At this point, participants were randomly assigned to one of two experimental conditions: ethical label or control condition. Following the presentation of the vignette, participants saw a photograph of a beer (see Figure 1) and completed the Beer Taste Perception Questionnaire, and then the MSIS. All participants completed the experiment in this order to (a) minimise the time between reading the label and answering questions about the beer, and (b) negate 
demand characteristics that might be present if the MSIS was presented before assessing expectations regarding the beer. Participation took approximately $10 \mathrm{~min}$.

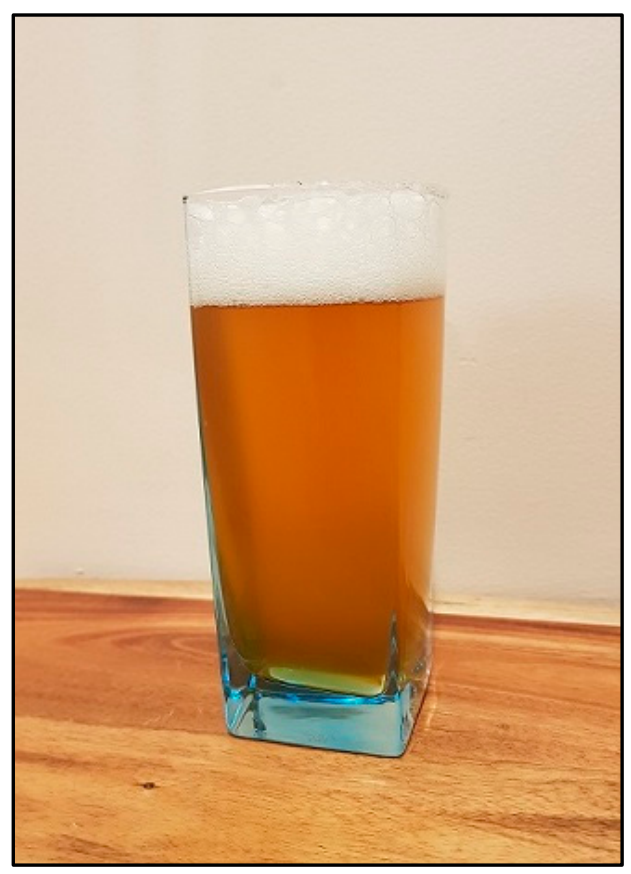

Figure 1. The photograph of the beer presented to participants.

\subsection{Design}

The study employed a mixed design to investigate the effects of both label type (i.e., ethical vs. control) and moral self-image on participants' ratings of the expected flavour and aroma characteristics of the beer (i.e., the dependent variables). Moral self-image and the ratings of beer were measured on continuous scales, while label type was a betweensubjects categorical variable. The data were analyzed using moderation analyses.

\subsection{Results}

\subsubsection{Preliminary Analyses}

Prior to conducting the moderation analyses, assumption testing was performed to ensure there were no violations of the sample size, normality, linearity, outliers, or multicollinearity assumptions. An examination of histograms, Q-Q plots, and standardised values indicated that each variable was normally distributed but there was one univariate outlier. This person was removed prior to analysis. All other assumptions were met and multiple imputation was performed to replace any missing data.

Participants in both groups rated the beer on eight different characteristics of taste/flavour and willingness to pay. Means and standard deviations for each of the variables are reported in Table 1 for the moral and control groups.

\subsubsection{Inferential Analyses}

Moderated regression analyses were conducted to determine whether the associations between ethical labelling and the dependent variables (i.e., pleasantness of taste, pleasantness of aftertaste, pleasantness of aroma, intensity of taste, sweetness, fruitiness, bitterness, quality, and willingness to pay) were influenced by participants' moral self-image. MSIS scores were mean centered prior to the analyses. After applying conservative corrections for multiple comparisons $(p<0.006)$, only the moderated regression analysis conducted on the 'intensity' ratings produced a significant result. It revealed that $7.17 \%$ of the variance in 'intensity' ratings was explained by the model consisting of label type, moral self-image, and the interaction between these variables, $F(3,166)=4.28, p=0.006$. As shown in Table 2, 
neither the type of label (i.e., ethical or control) nor moral self-image made a significant, unique contribution to the explanation. However, the interaction between label type and moral self-image was significant. Simple slopes analysis (see Figure 2) showed that when the ethical label was presented to participants, there was no significant association between moral self-image and intensity ratings, $t(166)=-0.72, p=0.47,95 \% \mathrm{CI}(-0.75,0.35)$. However, when the control label was presented to participants, there was a significant association between moral self-image and intensity ratings, $t(166)=3.08, p=0.002,95 \%$ CI $(0.28,1.29)$. The results indicate that when in the control label condition, but not the ethical label condition, higher levels of moral self-image are associated with higher levels of expected intensity of taste.

Table 1. Descriptive statistics for beer flavour characteristics for control and moral groups.

\begin{tabular}{ccccc}
\hline & \multicolumn{2}{c}{ Control } & \multicolumn{2}{c}{ Moral } \\
\hline Variables & M & SD & M & SD \\
\hline Pleasant taste & 6.33 & 2.12 & 6.61 & 2.01 \\
Pleasant aftertaste & 5.90 & 2.20 & 5.84 & 2.32 \\
Pleasant aroma & 6.32 & 1.96 & 6.76 & 2.18 \\
Sweetness & 4.76 & 2.07 & 5.00 & 2.14 \\
Bitterness & 5.52 & 1.96 & 5.77 & 1.81 \\
Fruitiness & 5.35 & 2.27 & 5.72 & 2.32 \\
Intensity & 5.92 & 1.95 & 6.34 & 1.58 \\
Quality & 6.15 & 1.93 & 6.31 & 1.72 \\
Willingness to pay (AUD) & 5.75 & 2.04 & 6.03 & 1.67 \\
MSIS Total & 7.44 & 0.70 & 5.06 & 0.84 \\
\hline
\end{tabular}

Table 2. Unstandardised regression coefficients for intensity ratings $(N=170)$.

\begin{tabular}{cccccc}
\hline & $\boldsymbol{B}$ & $\boldsymbol{S E}$ & $\boldsymbol{t}$ & $\boldsymbol{p}$ & $\mathbf{9 5 \%} \mathbf{C I}$ \\
\hline Constant & 6.13 & 0.13 & & & \\
Label Type & -0.40 & 0.27 & -1.48 & 0.138 & {$[-0.94,0.13]$} \\
MSIS & 0.35 & 0.19 & 1.84 & 0.07 & {$[-0.03,0.72]$} \\
Label Type * MSIS & 0.98 & 0.38 & 2.61 & $0.01 *$ & {$[0.24,1.73]$} \\
\hline
\end{tabular}

Note: MSIS = Moral Self-Image Scale; Label Type $=$ ethical label or control label. ${ }^{*} p<0.05$.

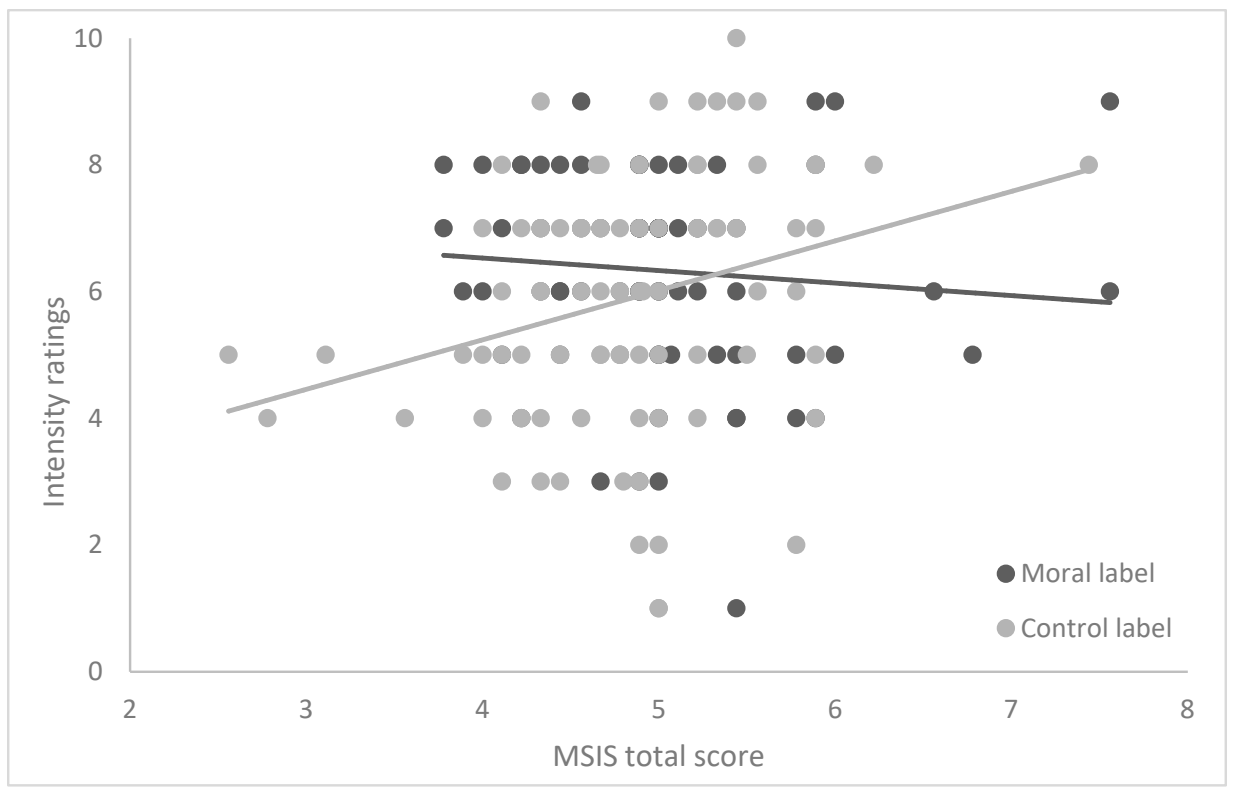

Figure 2. The interaction between moral self-image and label type on ratings of the beer's expected intensity. 


\section{Experiment Two: Perception}

\subsection{Method}

Participants

The participants were 59 individuals ( 38 men, 21 women) from the general population and students at a university in Victoria, Australia. These people had not taken part in Experiment 1 . They ranged in age from 19 to 78 years with a mean age of 40.78 years $(S D=13.17)$ and had to be over 18 years of age to participate. The majority of the participants self-reported that they consumed beer more than once a week $(32.2 \%)$, with the remainder consuming beer either (a) less than once a month $(27.1 \%)$, (b) more than once a month but less than once a week $(28.8 \%)$, or (c) once a week $(11.9 \%)$.

\subsection{Materials}

Prior to commencing the experiment, participants were presented with an information statement, and signed an informed consent form, which was kept separate from study materials/responses. The same surveys (i.e., a demographics questionnaire, the Beer Taste Perception Questionnaire, and the MSIS $(\alpha=0.84)$ ) and labels (ethical or control) used in Experiment One were used in Experiment Two, but instead of being presented onscreen, the vignettes were printed on a separate A4 page in the bundle of study materials handed to participants. Lastly, the refreshingness of the beer was included as an item as it is a commonly used beer descriptor [41], thus making it worthy of examination. Refreshingness is a sensory characteristic that describes how well beer quenches the thirst of, or reinvigorates, the consumer.

Beer

Sailor's Grave Draught beer was provided to participants in all experimental conditions. This craft beer contains $4.85 \%$ alcohol per $355-\mathrm{mL}$ can. The beer was refrigerated between $4{ }^{\circ} \mathrm{C}$ and $6{ }^{\circ} \mathrm{C}$ prior to the experiment. Manufactured by the Sailor's Grave Brewing Company, the beer is described as having subtle hops flavours and a crisp finish. This beer was selected over other more popular and highly advertised draught beers in an attempt to avoid participants recognizing the beer (though see [42] for evidence suggesting that people cannot identify different beers in blind taste tests).

\subsection{Procedure}

As per Experiment One, this study had ethical approval (Project number: A18-021) and participants gave their informed consent prior to participating. Participants were made aware of, and recruited to participate in, the experiment via social media advertisements and posters put up at university campuses. The experiment was conducted in a temperature-controlled room, with lights on and curtains drawn. Participants were randomly assigned to one of two experimental conditions: ethical label or control label. After reading an explanatory statement and signing a consent form, participants completed the demographics questionnaire and then read either the ethical or control label, depending on which condition they had been assigned. They were then presented with a beer and completed the Beer Taste Perception Questionnaire while tasting the beer. Participants then filled out the MSIS. Participation took approximately $10 \mathrm{~min}$. Participants consumed no more than half a can of beer ( 0.6 standard drinks) and those who were on provisional driver's licenses were advised not to drive for at least one hour.

\subsection{Results \\ 6.4.1. Preliminary Analyses}

Assumption testing analyses identified seven data points that were considered outliers (i.e., $>3$ SDs from the mean). Once these data points were removed, none of the other assumptions were violated (i.e., normality, linearity, multicollinearity). 
Participants in both groups rated the beer on nine different characteristics of taste/flavour and willingness to pay. Means and standard deviations for each of the variables are reported in Table 3 for the moral and control groups.

Table 3. Descriptive statistics for beer flavour characteristics for control and moral groups.

\begin{tabular}{ccccc}
\hline & \multicolumn{2}{c}{ Control } & & Moral \\
\hline Variables & $\mathbf{M}$ & SD & M & SD \\
\hline Pleasant taste & 7.17 & 1.79 & 6.97 & 1.66 \\
Pleasant aftertaste & 6.57 & 2.46 & 6.76 & 2.39 \\
Pleasant aroma & 6.86 & 1.68 & 7.34 & 1.76 \\
Sweetness & 5.03 & 2.14 & 5.45 & 2.25 \\
Bitterness & 4.97 & 1.83 & 4.97 & 2.23 \\
Fruitiness & 4.43 & 2.42 & 5.38 & 2.35 \\
Refreshingness & 7.34 & 1.70 & 7.14 & 1.96 \\
Intensity & 5.67 & 1.94 & 5.79 & 1.66 \\
Quality & 7.27 & 1.62 & 7.45 & 1.68 \\
Willingness to pay (AUD) & 5.86 & 1.47 & 5.61 & 1.60 \\
MSIS Total & 5.13 & 0.61 & 5.37 & 0.67 \\
\hline
\end{tabular}

\subsubsection{Inferential Analyses}

As with Experiment One, moderated regression analyses were conducted to determine whether the association between ethical labelling and the dependent variables were influenced by participants' moral self-image. After correcting for multiple comparisons, only the moderated regression analysis with 'refreshingness' as a dependent variable produced a significant result. It revealed that $17.8 \%$ of the variance in 'refreshingness' was explained by the type of label a company uses, (mean centered) moral self-image, and the interaction between these variables, $F(3,49)=3.55, p=0.021$. Although this analysis does not meet the conservative criteria for significance we adopted $(p<0.006)$, it does meet traditional standards for statistical significance. As shown in Table 4, neither the type of label (i.e., ethical or control), nor the interaction between label type and moral self-image, made a significant unique contribution to the explanation. However, moral self-image did make a significant unique contribution to the explanation. The results indicate that people who perceived themselves as having a high moral self-image rated the beer as being more refreshing than did people who perceived themselves as being low in moral self-image.

Table 4. Unstandardised regression coefficients for 'refreshingness' ratings $(N=53)$.

\begin{tabular}{cccccc}
\hline & $\boldsymbol{B}$ & $\boldsymbol{S E}$ & $\boldsymbol{t}$ & $\boldsymbol{p}$ & $\mathbf{9 5 \%} \mathbf{C I}$ \\
\hline Constant & 6.97 & 0.34 & & & \\
Label Type & 0.36 & 0.47 & 0.76 & 0.452 & $(-0.59,1.30)$ \\
MSIS & 1.65 & 0.52 & 3.19 & $0.003{ }^{* *}$ & $(0.61,2.69)$ \\
Label Type * MSIS & -1.43 & 0.77 & -1.87 & 0.068 & $(-2.98,0.11)$ \\
\hline Note: MSIS = Moral Self-Image Scale; Label Type $=$ ethical label or control label. ${ }^{*} p<0.05 .{ }^{* *} p<0.01$.
\end{tabular}

\section{General Discussion}

It was hypothesised that ethical labelling would influence the expected and perceived taste, flavour, and aroma attributes of beer. Based on previous research, it was hypothesised that those people provided with the ethical label would expect and perceive the beer to taste better (and be willing to pay more for it), compared to those exposed to the control label. This hypothesis was not supported. Secondly, considering work by Hahnel et al. [43] and O'Connor et al. [33], it was hypothesised that people scoring high on a measure of moral self-image would be willing to pay more for beer than would those people who scored lower. This hypothesis was not supported either. Here, however, people scoring high on a measure of moral self-image perceived the beer as being more refreshing than did those scoring lower. Lastly, it was hypothesised that when exposed to a beer label containing 
ethically-orientated information, participants scoring high on a measure of moral self-image would rate the beer as being of better quality, like it more, and be willing to pay more for it compared to participants scoring low on moral self-image. This hypothesis was not supported. However, results did indicate that there was a significant association between moral self-image and expected intensity of taste, which was moderated by label type.

\section{Expectations}

The results indicate that there is a significant association between moral self-image and intensity of taste ratings, which was moderated by label type. Specifically, we found that if a control label was presented to participants (i.e., a label that contained no 'ethical information' about contributing to the community), higher moral self-image was associated with higher expected intensity of taste. Thus, when paired with a label describing a highquality product, but without reference to ethical conduct, people believing themselves to be more virtuous expected the beer's flavour to be more intense. Conversely, those who perceived themselves as being low in morality expected it to be less intense. Here, perhaps a high moral self-image state makes one sensitive to detailed descriptions in some way. Thus, individuals scoring high on the moral self-image scale (i.e., those people predisposed to a high moral self-image state) expect the care and attention to detail (described in the control label) to lead to a more intense beer. The ethical label, however, primes those who score low on the moral self-image scale into a state of higher sensitivity to label descriptions. This would explain why people in the ethical label condition vary in their self-perceived morality, but this did not affect their rating of the beer's intensity. What is interesting, and unique, is that we have shown that moral self-image can positively influence expectations associated with beer when only an image and descriptive label are provided.

\section{Perception}

Consistently with other studies [44,45], we assessed how morality affects taste. Eskine et al. [44] showed that reading vignettes outlining virtuous behaviour resulted in a beverage being rated as relatively more delicious than did reading a neutral vignette. Consistent with this work, we found that morality influences sensory perception. Specifically, we found that a higher moral self-image elicited higher ratings of perceived refreshingness. Feelings-as-information theory $[46,47]$ may offer a theoretical explanation for the potential influence of morality on perception. Here, reading positively-framed vignettes (e.g., making a good beer or contributing to the community) may have primed people (consciously or unconsciously) to feel good about themselves (hold positive feelings about how moral they are), and this information may have been used as a source of information in judgments of the beer (those people who feel positive will rate the beer more positively, i.e., as being more refreshing). Clearly this explanation is speculative, but it is consistent with evidence showing that a manipulated mood impacts beer taste perception [39].

It is worth noting that previous ethical labelling research has focused on labels that are associated with manufacturing processes (e.g., organic, fair-trade ingredients, environmentally friendly production processes). In this sense, the product itself is viewed as virtuous, and thus reflects positive attributes (e.g., better quality). In contrast, in the current study, the ethical label used was unrelated to the product itself, and instead was associated with the allocation of profits to either the business owner or to the community (i.e., charity). Thus, the brewing company may be perceived as being virtuous, but the product itself is not. This suggests that ethical labelling may only influence consumer expectations and perceptions when the product itself is perceived as virtuous.

\section{Limitations and Future Directions}

The findings of this study should be considered with a few limitations in mind. Although the study has high ecological validity (i.e., labels were drawn from the marketplace), both portray the brewer favorably. Thus, the labels used here may have lacked sufficient power to detect an effect. Using a negative label might have been a more powerful manip- 
ulation but would reduce ecological validity. Another limitation of Experiment Two is the small sample size, which means the experiment is underpowered and the findings should be considered preliminary evidence that moral self-image influences perceived refreshingness. Furthermore, given the cross-sectional nature of the study, a limitation is that it is possible that subjective ratings of refreshingness influenced (short-term) moral self-image such that those who found the beer to be less refreshing rated themselves as being of lower moral integrity. This would be consistent with the findings of Eskine et al. [48], in that taste influences morality. Further work is needed in this area to address these limitations.

\section{Conclusions}

In this study we found evidence suggesting that people who rated themselves as being moral expect a beer to be of higher intensity when it is paired with a label that describes a high-quality product, but without emphasizing ethical information that portrays the brewer favorably. We also found preliminary evidence suggesting that people who rate themselves as being more moral perceive a beer to be more refreshing than those people who rate themselves as being low in terms of morality, regardless of the ethical information in the label description. This study is the first to demonstrate that certain types of ethical labels have no impact on the expected and perceived taste and aroma of beer, whereas the wording used on the labels themselves has a limited impact on beer expectations. Given the findings, there seems to be little point in including ethical information that portrays the brewer favorably on beer labels.

Author Contributions: Conceptualization, G.V.D., R.F., S.W., J.T., D.B., and C.M.; methodology, G.V.D., R.F., S.W., and J.T.; formal analysis, G.V.D.; investigation, J.T., G.V.D., and R.F.; resources, C.M.; writing—original draft preparation, G.V.D. and R.F.; writing-review and editing, G.V.D., R.F., S.W., J.T., D.B., and C.M.; project administration, G.V.D., R.F., S.W., J.T., D.B., and C.M. All authors have read and agreed to the published version of the manuscript.

Funding: This research received no external funding.

Institutional Review Board Statement: The study was conducted in accordance with the (Australian) National Health and Medical Research Council (NHMRC) National Statement on Ethical Conduct in Human Research, and the protocol was approved by Federation University Australia's Human Research Ethics Committee (Project number: A18-021).

Informed Consent Statement: Informed consent was obtained from all subjects involved in the study.

Data Availability Statement: The data presented in this study are available on request from the corresponding author. The data are not publicly available due to ethical restrictions.

Acknowledgments: The beer for this study was provided by Sailors Grave Brewing Company.

Conflicts of Interest: Authors Van Doorn, Ferguson, Watson, Timora, Berends, and Moore received beer for use in this study, provided by Sailors Grave Brewing Company. Author Moore is co-owner of Sailors Grave Brewing Company.

\section{Appendix A}

Beer Taste Perception Questionnaire

On the scales below, please indicate your feelings about the different characteristics of beer. Circle the number between the adjectives which best represents your feelings about beer. Please complete this as quickly and accurately as possible.

How pleasant would you rate the taste of the beer?

Not pleasant at all $\rightarrow 0 \rightarrow 1 \rightarrow 2 \rightarrow 3 \rightarrow 4 \rightarrow 5 \rightarrow 6 \rightarrow 7 \rightarrow 8 \rightarrow 9 \rightarrow 10 \rightarrow$ Extremely pleasant

How pleasant would you rate the aftertaste of the beer?

Not pleasant at all $\rightarrow 0 \rightarrow 1 \rightarrow 2 \rightarrow 3 \rightarrow 4 \rightarrow 5 \rightarrow 6 \rightarrow 7 \rightarrow 8 \rightarrow 9 \rightarrow 10 \rightarrow$ Extremely pleasant 
How sweet would you rate the taste of the beer?

Not sweet at all $\rightarrow 0 \rightarrow 1 \rightarrow 2 \rightarrow 3 \rightarrow 4 \rightarrow 5 \rightarrow 6 \rightarrow 7 \rightarrow 8 \rightarrow 9 \rightarrow 10 \rightarrow$ Extremely sweet

How bitter would you rate the taste of the beer?

Not bitter at all $\rightarrow 0 \rightarrow 1 \rightarrow 2 \rightarrow 3 \rightarrow 4 \rightarrow 5 \rightarrow 6 \rightarrow 7 \rightarrow 8 \rightarrow 9 \rightarrow 10 \rightarrow$ Extremely bitter

How fruity would you rate the taste of the beer?

Not fruity at all $\rightarrow 0 \rightarrow 1 \rightarrow 2 \rightarrow 3 \rightarrow 4 \rightarrow 5 \rightarrow 6 \rightarrow 7 \rightarrow 8 \rightarrow 9 \rightarrow 10 \rightarrow$ Extremely fruity

How refreshing would you rate the taste of the beer?

Not refreshing at all $\rightarrow 0 \rightarrow 1 \rightarrow 2 \rightarrow 3 \rightarrow 4 \rightarrow 5 \rightarrow 6 \rightarrow 7 \rightarrow 8 \rightarrow 9 \rightarrow 10 \rightarrow$ Extremely refreshing

How pleasant would you rate the aroma of the beer?

Extremely mild $\rightarrow 0 \rightarrow 1 \rightarrow 2 \rightarrow 3 \rightarrow 4 \rightarrow 5 \rightarrow 6 \rightarrow 7 \rightarrow 8 \rightarrow 9 \rightarrow 10 \rightarrow$ Extremely intense

How intense would you rate the taste of the beer?

Extremely mild $\rightarrow 0 \rightarrow 1 \rightarrow 2 \rightarrow 3 \rightarrow 4 \rightarrow 5 \rightarrow 6 \rightarrow 7 \rightarrow 8 \rightarrow 9 \rightarrow 10 \rightarrow$ Extremely intense

How would you describe the quality of the beer?

Extremely low quality $\rightarrow 0 \rightarrow 1 \rightarrow 2 \rightarrow 3 \rightarrow 4 \rightarrow 5 \rightarrow 6 \rightarrow 7 \rightarrow 8 \rightarrow 9 \rightarrow 10 \rightarrow$ Extremely high quality

The average price for a glass of beer is $\$ 5$. How much would you be willing to pay for a full glass of this beer?

\section{References}

1. Terrill, D.; Leith, R. Craft Beer in Australia: Going from Strength to Strength 2020. Available online: https://www2.deloitte.com/au/ en/pages/consumer-business/articles/craft-beer-australia-going-from-strength-to-strength.html (accessed on 30 March 2020).

2. Smith, S.; Farrish, J.; McCarroll, M.; Huseman, E. Examining the Craft Brew Industry: Identifying Research Needs. Int. J. Hosp. Beverage Manag. 2017, 1. Available online: http:/ / scholars.unh.edu/ijhbm/vol1/iss1/3 (accessed on 18 June 2021). [CrossRef]

3. Chaloupka, F.J.; Grossman, M.; Saffer, H. The effects of price on alcohol consumption and alcohol-related problems. Alcohol Res. Health J. Natl. Inst. Alcohol Abus. Alcohol. 2002, 26, 22-34.

4. Barnett, A.; Velasco, C.; Spence, C. Bottled vs. canned beer: Do they really taste different? Beverages 2016, 2, 25. [CrossRef]

5. Reinoso-Carvalho, F.; Velasco, C.; van Ee, R.; Leboeuf, Y.; Spence, C. Music influences hedonic and taste ratings in beer. Front. Psychol. 2016, 7, 636. [CrossRef] [PubMed]

6. Mirabito, A.; Oliphant, M.; Van Doorn, G.; Watson, S.; Spence, C. Glass shape influences the flavour of beer. Food Qual. Prefer. 2017, 62, 257-261. [CrossRef]

7. Sörqvist, P.; Hedblom, D.; Holmgren, M.; Haga, A.; Langeborg, L.; Nöstl, A.; Kågström, J. Who needs cream and sugar when there is eco-labeling? Taste and willingness to pay for "eco-friendly" coffee. PLoS ONE 2013, 8, e80719. [CrossRef] [PubMed]

8. Rhee, J.J.; Schein, C.; Bastian, B. The what, how, and why of moralization: A review of current definitions, methods, and evidence in moralization research. Soc. Pers. Psychol. Compass 2019, 13, 12511. [CrossRef]

9. Rozin, P. The process of moralization. Psychol. Sci. 1999, 10, 218-221. [CrossRef]

10. Enax, L.; Krapp, V.; Piehl, A.; Weber, B. Effects of social sustainability signaling on neural valuation signals and taste-experience of food products. Front. Behav. Neurosci. 2015, 9, 247. [CrossRef]

11. Jin, J.; Dou, X.; Meng, L.; Yu, H. Environmental-friendly eco-labeling matters: Evidences from an ERPs study. Front. Hum. Neurosci. 2018, 12. [CrossRef]

12. Visschers, V.H.; Siegrist, M. Does better for the environment mean less tasty? Offering more climate-friendly meals is good for the environment and customer satisfaction. Appetite 2015, 95, 475-483. [CrossRef]

13. Annunziata, A.; Ianuario, S.; Pascale, P. Consumers' attitudes toward labelling of ethical products: The case of organic and fair trade products. J. Food Prod. Mark. 2011, 17, 518-535. [CrossRef]

14. De Pelsmacker, P.; Driesen, L.; Rayp, G. Do consumers care about ethics? Willingness to pay for fair-trade coffee. J. Consum. Aff. 2005, 39, 363-385. [CrossRef]

15. Didier, T.; Lucie, S. Measuring consumer's willingness to pay for organic and fair trade products. Int. J. Consum. Stud. 2008, 32, 479-490. [CrossRef]

16. My, N.H.; Demont, M.; Van Loo, E.J.; de Guia, A.; Rutsaert, P.; Tuan, T.H.; Verbeke, W. What is the value of sustainably-produced rice? Consumer evidence from experimental auctions in Vietnam. Food Policy 2018, 79, 283-296. [CrossRef]

17. Vecchio, R.; Annunziata, A. Willingness-to-pay for sustainability-labelled chocolate: An experimental auction approach. J. Clean. Prod. 2015, 86, 335-342. [CrossRef]

18. Bacig, M.; Young, C.A. The halo effect created for restaurants that source food locally. J. Foodserv. Bus. Res. 2019, 22, 209-238. [CrossRef] 
19. Bratanova, B.; Vauclair, C.-M.; Kervyn, N.; Schumann, S.; Wood, R.; Klein, O. Savouring morality. Moral satisfaction renders food of ethical origin subjectively tastier. Appetite 2015, 91, 137-149. [CrossRef]

20. Samant, S.S.; Seo, H.-S. Quality perception and acceptability of chicken breast meat labeled with sustainability claims vary as a function of consumers' label-understanding level. Food Qual. Prefer. 2016, 49, 151-160. [CrossRef]

21. Napolitano, F.; Caporale, G.; Carlucci, A.; Monteleone, E. Effect of information about animal welfare and product nutritional properties on acceptability of meat from Podolian cattle. Food Qual. Prefer. 2007, 18, 305-312. [CrossRef]

22. Tang, S.; Arciniegas, C.; Yu, F.; Han, J.; Chen, S.; Shi, J. Taste moral, taste good: The effects of fairtrade logo and second language on product taste evaluation. Food Qual. Prefer. 2016, 50, 152-156. [CrossRef]

23. Sörqvist, P.; Haga, A.; Langeborg, L.; Holmgren, M.; Wallinder, M.; Nöstl, A.; Seager, P.B.; Marsh, J.E. The green halo: Mechanisms and limits of the eco-label effect. Food Qual. Prefer. 2015, 43, 1-9. [CrossRef]

24. Sörqvist, P.; Langeborg, L.; Marsh, J.E. Social desirability does not underpin the eco-label effect on product judgments. Food Qual. Prefer. 2016, 50, 82-87. [CrossRef]

25. Lotz, S.; Christandl, F.; Fetchenhauer, D. What is fair is good: Evidence of consumers' taste for fairness. Food Qual. Prefer. 2013, 30 , 139-144. [CrossRef]

26. Anderson, E.C.; Barrett, L.F. Affective beliefs influence the experience of eating meat. PLoS ONE 2016, 11, e0160424. [CrossRef]

27. Bray, H.J.; Ankeny, R. Happy chickens lay tastier eggs: Motivations for buying free-range eggs in Australia. Anthrozoös 2017, 30, 213-226. [CrossRef]

28. Lazzarini, G.A.; Zimmermann, J.; Visschers, V.H.; Siegrist, M. Does environmental friendliness equal healthiness? Swiss consumers' perception of protein products. Appetite 2016, 105, 663-673. [CrossRef] [PubMed]

29. Bird, K.; Hughes, D.R. Ethical consumerism: The case of "fairly-traded" coffee. Bus. Ethic A Eur. Rev. 2002, 6, 159-167. [CrossRef]

30. Hoek, J.; Roling, N.; Holdsworth, D. Ethical claims and labelling: An analysis of consumers' beliefs and choice behaviours. J. Mark. Manag. 2013, 29, 772-792. [CrossRef]

31. Jordan, J.; Leliveld, M.C.; Tenbrunsel, A.E. The moral self-image scale: Measuring and understanding the malleability of the moral self. Front. Psychol. 2015, 6. [CrossRef]

32. Monin, B.; Jordan, A.H. The dynamic moral self: A social psychological perspective. In Personality, Identity, and Character: Explorations in Moral Psychology; Narvaez, D., Lapsley, D., Eds.; Cambridge University Press: Cambridge, UK, 2009 ; pp. 341-354.

33. O'Connor, E.L.; Sims, L.; White, K.M. Ethical food choices: Examining people's fair trade purchasing decisions. Food Qual. Prefer. 2017, 60, 105-112. [CrossRef]

34. Vanderhaegen, B.; Neven, H.; Coghe, S.; Verstrepen, K.J.; Derdelinckx, G.; Verachtert, H. Bioflavoring and beer refer-mentation. Appl. Microbiol. Biotechnol. 2003, 62, 140-150. [CrossRef]

35. Verbelen, P.J.; De Schutter, D.P.; Delvaux, F.; Verstrepen, K.J.; Delvaux, F.R. Immobilized yeast cell systems for continuous fermentation applications. Biotechnol. Lett. 2006, 28, 1515-1525. [CrossRef]

36. Smith, G.D. Beer: A Global History; Reaktion Books: London, UK, 2014.

37. Oliver, G. The Oxford Companion to Beer; Oxford University Press: Oxford, UK, 2011.

38. Rudnitskaya, A.; Polshin, E.; Kirsanov, D.; Lammertyn, J.; Nicolaï, B.; Saison, D.; Delvaux, F.R.; Delvaux, F.; Legin, A. Instrumental measurement of beer taste attributes using an electronic tongue. Anal. Chim. Acta 2009, 646, 111-118. [CrossRef]

39. Desira, B.; Watson, S.; Van Doorn, G.; Timora, J.; Spence, C. Happy hour? A preliminary study of the effect of induced joviality and sadness on beer perception. Beverages 2020,6,35. [CrossRef]

40. Little Gippsland Brewing Company. Little Gippsland Brewing. Available online: https:/ /www.littlegippslandbrewing.com.au/. (accessed on 16 June 2021).

41. Guinard, J.-X.; Souchard, A.; Picot, M.; Rogeaux, M.; Sieffermann, J.-M. Determinants of the thirst-quenching character of beer. Appetite 1998, 31, 101-115. [CrossRef]

42. Allison, R.I.; Uhl, K.P. Influence of beer brand identification on taste perception. J. Mark. Res. 1964, 1, 36-39. [CrossRef]

43. Hahnel, U.J.J.; Arnold, O.; Waschto, M.; Korcaj, L.; Hillmann, K.; Roser, D.; Spada, H. The power of putting a label on it: Green labels weigh heavier than contradicting product information for consumers' purchase decisions and post-purchase behavior. Front. Psychol. 2015, 6. [CrossRef]

44. Eskine, K.J.; Kacinik, N.A.; Webster, G.D. The bitter truth about morality: Virtue, not vice, makes a bland beverage taste nice. PLOS ONE 2012, 7, e41159. [CrossRef]

45. Skarlicki, D.P.; Hoegg, J.; Aquino, K.; Nadisic, T. Does injustice affect your sense of taste and smell? The mediating role of moral disgust. J. Exp. Soc. Psychol. 2013, 49, 852-859. [CrossRef]

46. Schwarz, N.; Clore, G.L. Mood, misattribution, and judgments of well-being: Informative and directive functions of affective states. J. Pers. Soc. Psychol. 1983, 45, 513-523. [CrossRef]

47. Schwarz, N. Feelings-as-information theory. In Handbook of Theories of Social Psychology; Van Lange, P., Kruglanski, A., Higgins, E.T., Eds.; Sage: Newbury Park, CA, USA, 2012; pp. 289-308.

48. Eskine, K.J.; Kacinik, N.A.; Prinz, J.J. A bad taste in the mouth. Psychol. Sci. 2011, 22, 295-299. [CrossRef] [PubMed] 